\title{
Neuraminidase Deficiency
}

National Cancer Institute

\section{Source}

National Cancer Institute. Neuraminidase Deficiency. NCI Thesaurus. Code C125596.

An autosomal recessive inherited lysosomal storage disease characterized by excessive intracellular accumulation and urinary excretion of sialic acid associated with neuraminidase deficiency. 